\title{
Variação na durabilidade da estrutura com a utilização do concreto autocicatrizante
}

\begin{tabular}{|c|}
\hline MARIANA SILVA FERREIRA - ENGENHEIRA, AuXILIAR DE COORDENAÇÃo \\
\hline GUSTAVO LOMBARDO - ENGENHEIRO \\
\hline MARCOS LUI GEH - ENGENHEIRO \\
\hline CASSIA SILVEIRA DE ASSIS - Professora Doutora, Coord. dA Engenharia CiviL \\
\hline
\end{tabular}

Centro Universitário do Instituto Mauá de Tecnologia

\author{
CLÁUDIO NEVES OURIVES - ENGENHEIRO, DIRETOR EXECUTIVO \\ EMILIO MINORU TAKAGI - Engenhelio Me., DiReTor TÉcnICO \\ Penetron Internacional
}

\section{RESUMO}

O CONCRETO AUTOCICATRIZANTE É OBTIDO PELA UTILIZAÇÃO DO ADITIVO REDUTOR DE PERMEABILIDADE POR CRISTALIZAÇÃO CAPILAR E É UM MATERIAL VIÁVEL PARA A OBTENÇÃO DE ESTRUTURAS QUE POSSUEM MAIOR DURABILIDADE. UM TRAÇO USUAL DE CONCRETO FOI REALIZADO UTILIZANDO O ADITIVO MENCIONADO, FORAM REALIZADOS DOIS PROCESSOS DE CURA LONGA, COM E SEM APLICAÇÃO DE CARGA PARA FISSURAÇÃO DO CORPO DE PROVA. ANALISOUSE A RESISTÊNCIA À COMPRESSÃO, CARBONATAÇÃO ACELERADA, O AUMENTO DE DURABILIDADE NA ESTRUTURA AUTOCICATRIZANTE E O SEU COBRIMENTO

EQUIVALENTE. FoI POSSÍVEL AFIRMAR QUE A UTILIZAÇÃO DO ADITIVO NÃO GERA DIFERENÇA SIGNIFICATIVA NA RESISTÊNCIA À COMPRESSÃO, INDEPENDENTE DO tipo de cura realizada. Para a carbonataÇão acelerada houve uma REDUÇÃO NA PENETRAÇÃO DE 2 MM EM RELAÇÃO AO CONCRETO REFERÊNCIA, RESULTANDO EM UM AUMENTO DE 47\% DA DURABILIDADE. PARA O COBRIMENTO EQUIVALENTE OBTEVE-SE UMA DIMINUIÇÃO SIGNIFICATIVA QUANDO UTILIZADO O CONCRETO AUTOCICATRIZANTE, VARIANDO ENTRE 0,7 E 1,4 CM DEPENDENDO DA AGRESSIVIDADE DO AMBIENTE.

Palavras-chave: aditivo redutor de permeabilidade por cristalização capilar, autocicatrizante, carbonatação, cobrimento, durabilidade.

\section{INTRODUÇÃO}

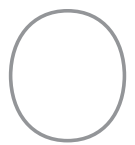

crescimento da população mundial faz com que o número de edificações

e obras de arte com estruturas predominantemente de concreto cresça. Simultaneamente, a preocupação com sua manutenção ao longo do tempo também passa a ter destaque. Isso faz com que a durabilidade do material utilizado se torne cada vez mais um fator determinante para a aprovação do projeto final.

No entanto, o conceito de durabilidade ainda é muito subjetivo, pois essa propriedade está relacionada a muitos fatores que não são constantes para nenhuma estrutura como, por exemplo, o material utilizado, o ambiente em que a estrutura se encontra e as condições de uso e manutenção.

Mesmo não sendo amplamente abordada nas normativas brasileiras existentes, a principal forma adotada para quantificação da durabilidade da estrutura é o cálculo do período necessário para os agentes agressivos penetrarem na estrutura, chegando nas barras de aço internas. Quando isso ocorre o material passa pelo processo de despassivação, iniciando o processo de corrosão do aço, que, quando avançado, reduz consideravelmente a seção transversal resistente da armadura, gerando perda de aderência, podendo chegar ao desplacamento do cobrimento e a completa exposição do aço [1].
Sendo a corrosão das armaduras um dos principais fatores que comprometem a utilização e segurança das estruturas, se torna necessário o estudo das principais causas dessa degradação. Uma dessas causas é a carbonatação, que ocorre quando o gás carbônico entra em contato com o concreto, que é capaz de reabsorver entre 3 e 5\% do $\mathrm{CO}_{2}$ emitido durante a produção do cimento [2]. A carbonatação poderia ser desejável se não gerasse a redução da alcalinidade do concreto e a consequente despassivação do cobrimento da armadura, gerando a corrosão do material.

Desse modo, a durabilidade pode ser comparada ao período necessário para que o processo de carbonatação 
atinja a armadura, ou seja, o dióxido de carbono penetre toda a espessura do cobrimento da estrutura, encontrando o material metálico. Sendo assim, uma das maneiras de aumentar a vida útil do concreto é limitar a entrada dos agentes agressivos. No entanto, deve se considerar que esse desempenho depende diretamente da facilidade em que líquidos ou gases penetram no concreto e que a fissuração do material acelera esse processo [3].

Uma das soluções viáveis está na utilização do aditivo redutor de permeabilidade por cristalização capilar no traço do concreto, transformando-o em concreto autocicatrizante. Esse material vem sendo estudado há alguns anos e já foi empregado em construções de notoriedade como a cobertura fluida do Museu de Arte do Rio (M.A.R.) e a laje de subpressão do Museu da Imagem e do Som (M.I.S.), ambas no Rio de Janeiro [4]. Teve sua eficiência comprovada, incluindo a confirmação de que sua utilização aumenta a taxa de concreção, reduzindo tanto o tamanhos dos poros como a porosidade total do material [5].

Esse aditivo reage com a umidade e com os produtos da hidratação do cimento, formando uma estrutura cristalina insolúvel nos poros e capilares do concreto capaz de selar as fissuras e inibir a penetração de agentes agressivos. É constituído por cimento Portland, compostos químicos ativos e rastreador químico. Sabe-se que é necessário a exposição do concreto autocicatrizante à água para que esse processo ocorra com maior eficiência, sendo comprovado que a exposição do material a ciclos úmidos e secos é recomendada para a autocicatrização [4].
Foram analisadas as alterações que ocorrem pela utilização do aditivo redutor de permeabilidade por cristalização capilar na carbonatação do material pelo ensaio laboratorial de carbonatação acelerada e na resistência à compressão. O ensaio de carbonatação acelerada permitiu a obtenção da profundidade de penetração do gás carbônico e seu coeficiente de carbonatação. A partir desses dados foi possível determinar a vida útil de projeto ou sua durabilidade, seguido pelo cálculo do cobrimento equivalente do concreto autocicatrizante, ou seja, o cobrimento capaz de gerar a mesma proteção na estrutura ao ser comparado com o concreto usual, ou de referência.

\section{MATERIAIS E PROGRAMA EXPERIMENTAL}

Todos os corpos de prova foram moldados utilizando os seguintes materiais: areia média lavada, brita 0 e brita 1 como agregados; cimento Portland composto CP II-E-32 RS; aditivo redutor de água tipo 2 (RA2) na dosagem de 0,35\% e aditivo redutor de permeabilidade por cristalização capilar na do-

\section{Cura 1}

Figura 1

Descrição dos métodos de cura utilizados

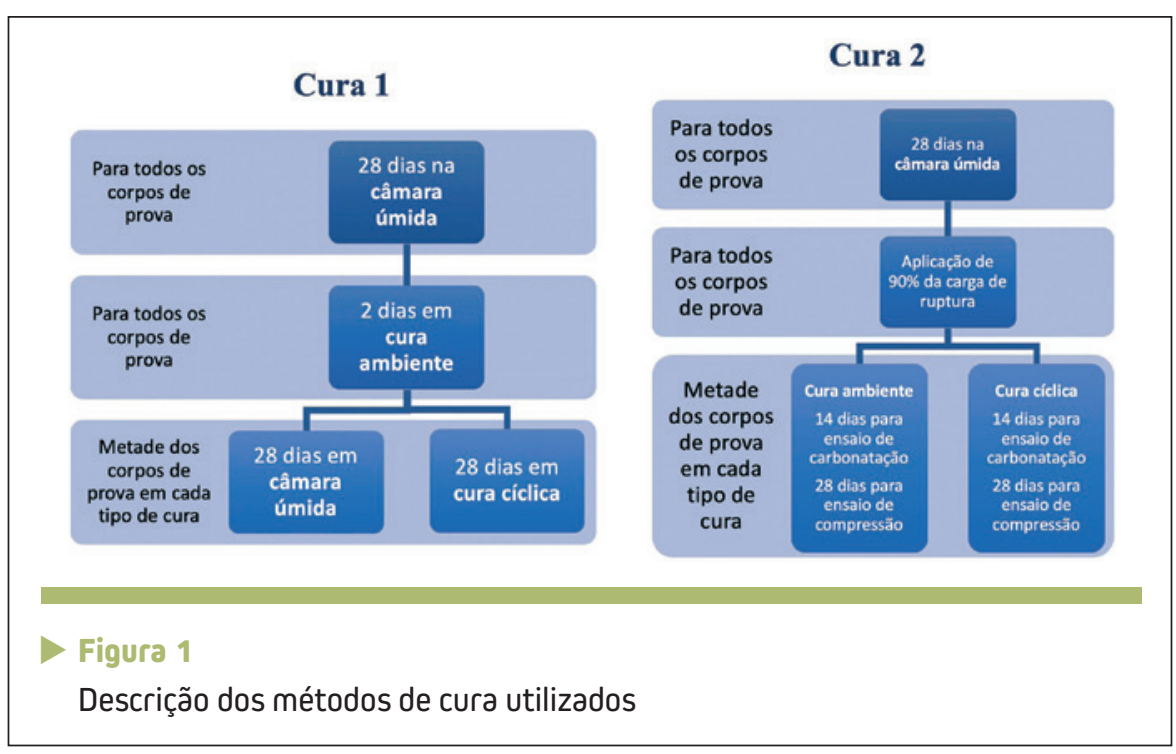

sagem de 0,8\%, ambos em relação a massa de cimento.

A determinação do traço foi realizada pelo método do IBRACON e o traço utilizado foi de 1:1, 8:2, 7:0, 52 sendo, respectivamente, cimento, areia, brita 0, brita 1 e a relação água/ cimento. Foram produzidas amostras de concreto referência e autocicatrizante. A moldagem dos corpos de prova foi realizada de acordo com a norma NBR 5738 (2015).

Foram realizados dois processos de cura distintos, denominados cura 1 e cura 2, descritos na Figura 1. O primeiro foi uma cura longa, sem aplicação de carga, a fim de identificar as alterações desse aditivo no concreto realizando os procedimentos de cura padrão em laboratórios. O segundo analisou as variações das propriedades para o concreto fissurado, buscando uma correlação com os períodos e condições usuais em obras.

Para ambos os processos, a cura cíclica foi aplicada, consistindo na cura dos corpos de prova imersos em água até sua metade durante 4 dias, sendo invertidos após esse período, alternando seu topo com a base. Esse procedi- 
mento é realizado durante um período total de 28 dias e tem como função permitir a interação da água com o dióxido de carbono e com os materiais não hidratados.

Para a cura 1, os corpos de prova desmoldados foram mantidos na câmara úmida, com $80 \pm 10 \%$ de umidade relativa, durante 28 dias. Após esse período permaneceram por 2 dias no ambiente do laboratório e, em seguida, retornaram para a câmara úmida, onde apenas metade dos corpos de prova foram submetidos a cura cíclica. A cura 1 foi utilizada para as análises de resistência à compressão, a fim de observar o material pelos parâmetros usuais de laboratório.

A cura 2 passou pelos primeiros 28 dias na câmara úmida, em condições idênticas as descritas na cura 1. Após essa etapa, aplicou-se 90\% da carga de ruptura, variando de 42 a $43 \mathrm{MPa}$. Essa carga foi aplicada com a finalidade de gerar microfissuras nos corpos de prova, tais fissuras simulam os efeitos de temperatura, dilatação do concreto e esforços de carregamento. Os corpos de prova fissurados foram levados para a segunda parte da cura, onde metade deles permaneceu em local com temperatura e umidade ambiente e a outra metade passou pela cura cíclica. O tempo que os corpos de prova permaneceram na segunda parte da cura diferiu para cada ensaio, sendo 14 dias para o ensaio de carbonatação acelerada e 28 dias para o ensaio de resistência à compressão.

A análise da resistência à compressão dos corpos de prova seguiu a norma NBR 5739 (2018). O ensaio foi realizado após a primeira e a última etapa de ambos os processos de cura, ou seja, após os 28 dias usuais e aos 58 dias para a cura 1 e 56 dias para a cura 2.

O ensaio de carbonatação acelerada foi realizado ao final do período de cura 2. Por não ser um ensaio normatizado, sua metodologia foi desenvolvida pelo laboratório que realizou o experimento. Os corpos de prova foram mantidos na câmara de carbonatação durante 4 semanas consecutivas, com temperatura de $23 \pm 2{ }^{\circ} \mathrm{C}$, umidade de $65 \pm 5 \%$ e teor de $\mathrm{CO}_{2}$ de $5 \pm 1 \%$. Foram realizadas medidas de profundidade de carbonatação a cada 7 dias.

Para a realização das medidas, o corpo de prova foi cortado a cada semana, obtendo-se um pedaço de $4 \mathrm{~cm}$, onde foi pulverizado uma solução indicadora de fenolftaleína na concentração de 1\% sobre a face que não estava em contato direto com a câmara. Esse procedimento permite a visualização da profundidade de penetração do dióxido de carbono de acordo com a medida da borda que não tem sua cor
Tabela 1 - Resultados de resistência à compressão

\begin{tabular}{|c|ccc|}
\hline Cura & Tempo & Referência & Autocicatrizante \\
\hline \multirow{4}{*}{1} & 28 dias & 43,6 & 43,6 \\
\cline { 2 - 3 } & Cura na câmara úmida 58 dias & 51,1 & 52,1 \\
\hline \multirow{2}{*}{2} & Cura cíclica 58 dias & 50,8 & 52,9 \\
\cline { 2 - 3 } & 28 dias & 48,7 & 48,8 \\
\hline & Cura ambiente 56 dias & 54,8 & 52,6 \\
\hline & Cura cíclica 56 dias & 49,6 & 51,2 \\
\hline
\end{tabular}

alterada pela aplicação da fenolftaleína. Apenas a parte alcalina do material fica com uma cor rosada após a aplicação. A medida da profundidade de carbonatação é realizada em diferentes pontos do corpo de prova, obtendo-se a profundidade média de carbonatação, em milímetros.

Utilizou-se o modelo de Tuutti, um dos modelos mais aceitos para o cálculo da penetração de agentes agressivos no concreto [1]. No entanto, não foi possível utilizá-lo diretamente, pois o ensaio realizado é acelerado, por esse motivo a equação para obtenção do tempo de ensaio foi adaptada pelo laboratório e está descrita na equação 1 .

$e_{c}=k \cdot \sqrt{t \cdot 0,4566}$

Sendo: $e_{c}$, a profundidade média de carbonatação em mm; k, o coeficiente de carbonatação [mm/ano $\left.{ }^{0,5}\right]$ e t, o tempo de ensaio/durabilidade em ano.

Com as profundidades de carbonatação e seus respectivos tempos de ensaio, foi possível determinar o coeficiente de carbonatação. Com esse coeficiente, é possível encontrar o tempo de vida útil ou a durabilidade da estrutura, admitindo-se o valor de cobrimento como a profundidade máxima para esse período. Foi utilizado o valor de 2,5 cm para calcular o tempo necessário para a despassivação por carbonatação.

\section{RESULTADOS E DISCUSSÕES}

Todos os resultados de resistência à compressão se encontram na Tabela 1. Para a cura 1, fica evidente que, aos 28 dias, não houve diferença de resistência entre o concreto referência e o concreto autocicatrizante. O aumento na resistência dos 
corpos de prova aos 58 dias ocorre devido ao maior tempo de cura, possibilitando a obtenção de uma maior resistência quando comparada com os 28 dias. No entanto, para o concreto referência em cura na câmara úmida, houve uma diminuição em $0,67 \%$ em comparação com a cura cíclica, e, para o concreto autocicatrizante, ocorreu um aumento de 1,42\% na resistência do corpo de prova submetido à cura cíclica. Essas pequenas variações podem ser decorrentes da variabilidade do material e do processo de confecção do concreto, não sendo significativas.

A cura 2 também não obteve diferenças significativas na resistência à compressão aos 28 dias, o que era esperado, já que o processo de cura dessa primeira parte é idêntico em ambos os casos. Aos 58 dias, é possível observar uma diminuição da resistência à compressão em 4,08\% para o concreto autocicatrizante na cura ambiente e um aumento de $3,03 \%$, para o concreto autocicatrizante, na cura cíclica. Com isso, foi possível concluir que não houve al-

\begin{tabular}{|c|c|c|c|}
\hline Tipo do concreto & $\begin{array}{c}\text { Profundidade média } \\
\text { de carbonatação } \\
{[\mathrm{mm}]}\end{array}$ & $\begin{array}{c}\text { Coeficiente de } \\
\text { carbonatação }-\mathrm{k} \\
{\left[\mathrm{mm}^{2} / \mathrm{ano}\right]}\end{array}$ & $\begin{array}{c}\text { Durabilidade da } \\
\text { estrutura [anos] }\end{array}$ \\
\hline \begin{tabular}{c} 
Referência cura ambiente \\
\hline $\begin{array}{c}\text { Autocicatrizante } \\
\text { cura ambiente }\end{array}$
\end{tabular} & 8,48 & 2,37 & 111,1 \\
\hline $\begin{array}{c}\text { Referência cura cíclica } \\
\text { Autocicatrizante } \\
\text { cura cíclica }\end{array}$ & 6,14 & 1,72 & 211,7 \\
\hline
\end{tabular}

terações significativas de resistência para o concreto com a fissuração, independente da cura. Esse resultado é relevante para comprovar que a utilização do aditivo redutor de permeabilidade por cristalização capilar não causa nenhuma alteração indesejada na resistência do concreto.

Os ensaios de profundidade de carbonatação foram realizados apenas para a cura 2, visando a utilização do processo de cura que mais se aproxima das condições reais de uma obra civil. Os resultados obtidos durante as 4 semanas de ensaio são apresentados na Figura 2.

Ao analisar os valores de profundidade de carbonatação, é possível verificar que as variações que ocorreram entre o concreto referência e o autocicatrizante tiveram uma constância de, aproximadamente, 0,5 $\mathrm{mm}$ para as duas primeiras semanas

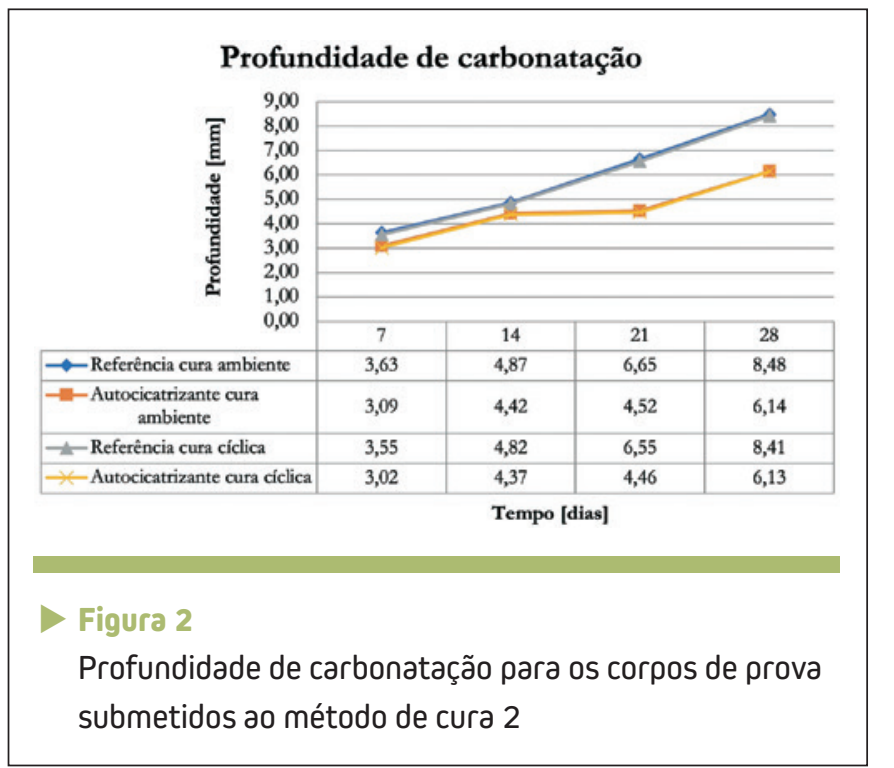
e $2 \mathrm{~mm}$ a partir de 21 dias. A cura cíclica e ambiente não sofreram variações significativas entre si, para a carbonatação, não houve uma interferência relevante do tipo de cura escolhido. No entanto, a presença do aditivo redutor de permeconfirmando que, abilidade por cristalização capilar reduziu significativamente a profundidade de carbonatação a partir da terceira semana.

A baixa redução da profundidade de carbonatação entre o concreto referência e o autocicatrizante nas primeiras semanas pode ser explicada pela alta resistência do traço de concreto utilizado, o que gera, naturalmente, uma redução da penetração de gás carbônico.

A partir da terceira semana, o concreto referência continua mantendo um crescimento constante em sua profundidade carbonatada, enquanto o concreto autocicatrizante cresce em menor proporção, ficando praticamente estável entre a segunda e a terceira semana. Esse comportamento pode estar relacionado à ação do aditivo.

A durabilidade do material foi calculada de acordo com as profundidades de carbonatação da quarta semana, 28 dias. Foram utilizados esses valores devido ao aumento da precisão dos resultados com o aumento do tempo de ensaio, por terem um maior tempo de exposição e permanência na câmara de carbonatação. Os resultados para os coeficientes de carbonatação e a durabilidade da estrutura se encontram na Tabela 2.

A alteração da durabilidade para a estrutura com concreto autocicatrizante foi calculada fixando-se o cobrimento de $2,5 \mathrm{~cm}$ e resultou em um aumento de $47,54 \%$ para a cura ambiente e de $46,80 \%$ para a cura 


\begin{tabular}{|c|c|}
\hline Tabela 3 - Dados utilizados para \\
Cada classe de agressividade
\end{tabular}

cíclica, ou seja, o tipo de cura não foi significativo para essa propriedade e a durabilidade da estrutura teve um aumento muito significativo.

A fim de estimar o cobrimento necessário do concreto autocicatrizante para manter a mesma durabilidade do concreto referência, recalculou-se o tempo de vida útil fixando-se os valores de cobrimento descritos na norma ABNT NBR 6118 (2014) e divididos em quatro classes, sendo a classe 1 a menos agressiva ao concreto e a classe 4 a mais agressiva como, por exemplo, construções com contato contínuo e direto com o mar.

Com os valores de cobrimento fixos, encontrou-se a durabilidade para o concreto referência.

Utilizando o valor de durabilidade encontrado e alterando o valor do coeficiente de carbonatação para o do concreto autocicatrizante, foi possível encontrar o cobrimento necessário para esse material. Os dados de tempo e cobrimento utilizados para cada classe estão descritos na Tabela 3. Os cobrimentos equivalentes estão descritos na Figura 3.

É possivel
observar que o
cobrimento equi-

Figura 3

Gráfico do cobrimento equivalente

\section{cobrimento equi-}

valente para o concreto autocicatrizante teve uma diminuição para cada classe de 0,7 cm, 0,8 cm, 1,1 cm e 1,4 $\mathrm{cm}$, respectivamente. A diminuição do cobrimento aumenta de acordo com o aumento da classe, o que é muito significativo economicamente, devido à necessidade de uma maior espessura para essas classes de maior agressividade. Como nos outros casos analisados, não houve diferenças significativas entre os tipos de cura.

\section{CONCLUSÕES}

Com os resultados obtidos foi possível concluir que:

> Os diferentes métodos de cura não geraram alterações relevantes em nenhum dos ensaios realizados;

> A utilização do aditivo redutor de permeabilidade por cristalização capilar não causa alteração significativa na resistência à compressão do material;

- Houve uma redução considerável no coeficiente de carbonatação para o concreto autocicatrizante;

- A utilização do aditivo redutor de permeabilidade por cristalização capilar gerou um aumento da durabilidade da estrutura estimado em 47\% quando comparada ao material referência;

Seria possível reduzir o cobrimento necessário para a obtenção do mesmo tempo de vida útil da estrutura ao utilizar o concreto autocicatrizante, gerando uma economia considerável para grandes estruturas de concreto armado.

\section{AGRADECIMENTOS}

Agradecemos a empresa Penetron Brasil Ltda. por compartilhar seus conhecimentos e seu produto, além dos laboratórios da Associação Brasileira do Cimento Portland (ABCP) e Testin Tecnologia de Materiais Ltda., por concederem os ensaios realizados na pesquisa.

\section{DREFERÊNCIAS BIBLIOGRÁFICAS}

[1] Medeiros MHF de, Andrade JJ de 0, Helene P. Durabilidade e Vida Útil das Estruturas de Concreto. In: Isaia GC (ed) Concreto: Ciência e Tecnologia. IBRACON, 2011 , p. 37.

[2] Claisse PA. Introduction to cement and concrete. In: Civil Engineering Materials. Oxford: Elsevier, pp. 155-162.

[3] Byoungsun P, Young CC. Investigating a new method to assess the self-healing performance of hardened cement pastes containing supplementary cementitious materials and crystalline admixtures. J Mater Res Technol 2019; 8: 6058-6073.

[4] Takagi EM, Lima MG, Helene P. Concretos autocicatrizantes com cimentos brasileiros de escória de alto forno ativados por catalisador cristalino. Concreto \& Construções, 2014, pp. 75-79.

[5] Zheng K, Yang X, Chen R, et al. Application of a capillary crystalline material to enhance cement grout for sealing tunnel leakage. Constr Build Mater 2019; 214: 497-505. 